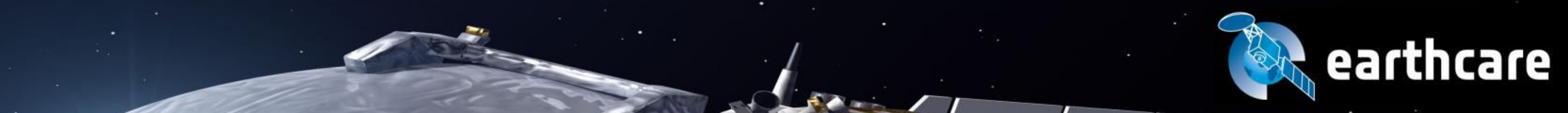

ATLID, ESA Atmospheric LIDAR: integration of instrument and tests

de Villele $G 1$, Pereira Do Carmo J 2 , Helière A 2 , Lefebvre A 2, Barbaro L 1 , Belhadj $T 1$, Chassat $F$ 1, Corselle B 1, Evin R 1, Feral M 1, Levret I 1, Lingot P 1, Olivier F 1, Pelletier S 1, Pochet J 1 , Schaube A 1 , Varlet $F 1$, Vlimant P1

1 Airbus Defence And Space, Toulouse, France

2 European Space Agency - ESTEC., Nordwijk, The Netherlands

DEFENCE AND SPACE

International Conference on Space Optics 2018, Chania, Oct 2018 


\section{Presentation content}

- ATLID and EarthCARE misson

- ATLID design and development

- ATLID flight model testing

- Mechanical test

- Radiometric test

- Detection test

- Functional test

- ATLID final integration steps

- ATLID environmental test campaign 
- ATLID and EarthCARE misson

- ATLID design and development

- ATLID flight model testing

- Mechanical test

- Radiometric test

- Detection test

- Functional test

- ATLID final integration steps

- ATLID environmental test campaign 


\section{EarthCARE Mission}

- EarthCARE satellite is the $6^{\text {th }}$ ESA explorer mission

- Quantify aerosol and cloud radiation interactions to improve numerical modelling for climate and weather forecast

- 4 instruments:

- CPR: 94GHz cloud profiling radar

- ATLID: UV atmospheric Lidar

- MSI : multispectral imager

- BBR: broadband radiometer

- Satellite requirements

- Sun synchronous orbit (14:00 desc.mode)

- Orbit mean spherical altitude $393 \mathrm{~km}$

- Repeat cycle of 25 days

- Design lifetime of 3 years
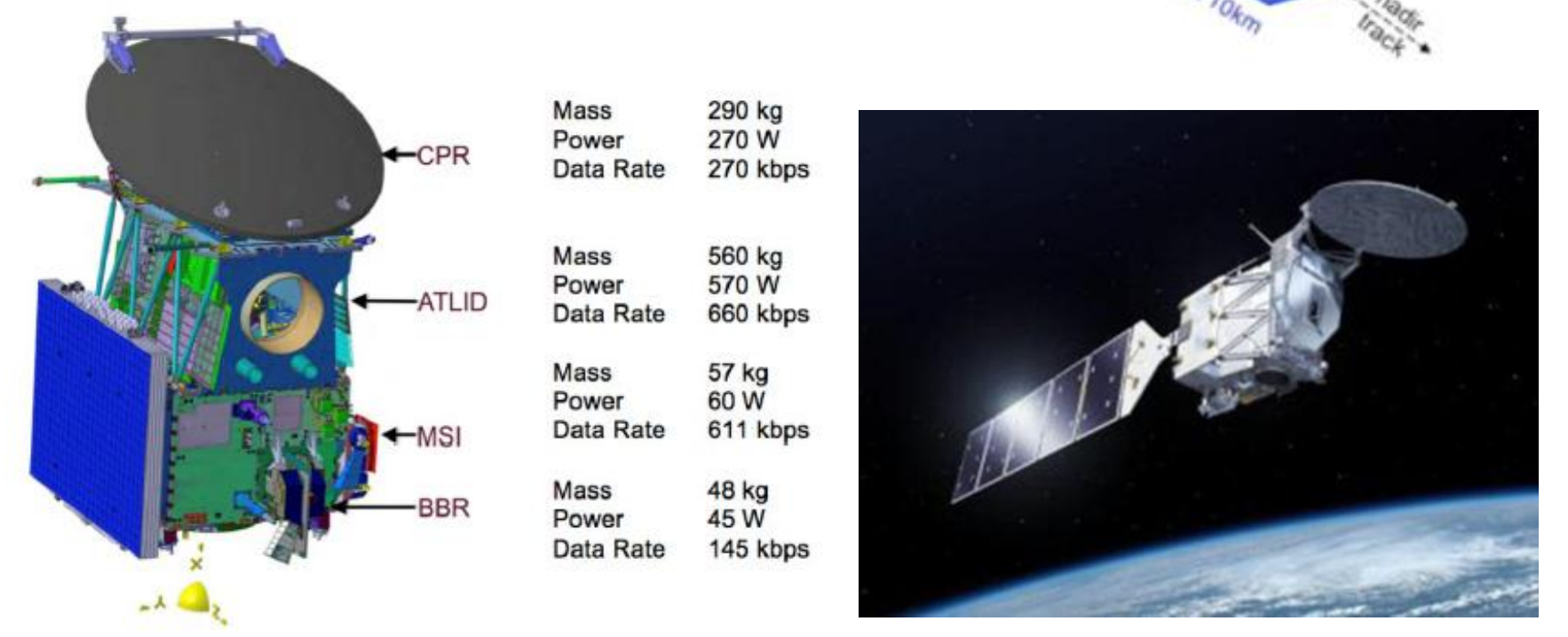

ATLID esa AIRBUS 


\section{ATLID instrument mission}

- Atmospheric LIDAR with $355 \mathrm{~nm}$ source

- Measurement of vertical profile of optically thin clouds and aerosol layers

- Vertical profile from 0 to $40 \mathrm{~km}$, resolution from 100 to $500 \mathrm{~m}$

- Horizontal sampling at $280 \mathrm{~m}$

- Detection with High Spectral Resolution Etalon technique

- Fabry Perot Etalon separate narrow bandwidth backscattered Mie signal from the broadband Rayleigh signal

- Co and Cross polarisation signal separation.

- 3 science channels

- Mie Co polarisation-> aerosol and thin clouds backscatter

- Rayleigh Co polarisation -> molecular backscatter

- Cross polarisation -> polarisation ratio of backscatter
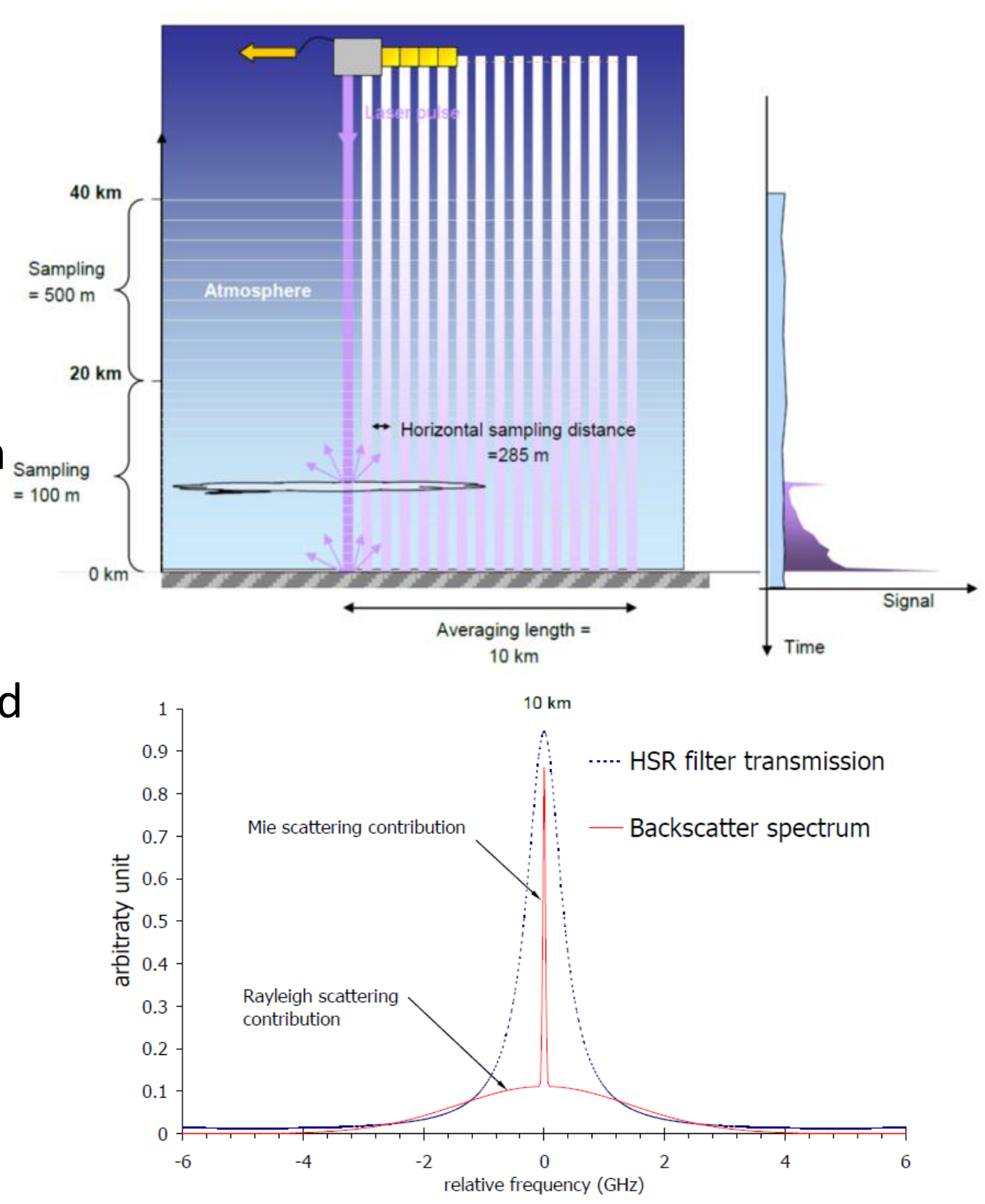
- ATLID and EarthCARE misson

- ATLID design and development

- ATLID flight model testing

- Mechanical test

- Radiometric test

- Detection test

- Functional test

- ATLID final integration steps

- ATLID environmental test campaign 


\section{ATLID instrument design}

- Bistatic architecture: separate transmitter and receiver, with active co-alignment loop.

- Transmitter:

- Pressurized power laser head 40mJ @51Hz, seeded by frequency adjustable reference laser and with beam steering mechanism

- Beam expander and external baffle to protect from contamination

- Fully redundant equipments.

- Receiver
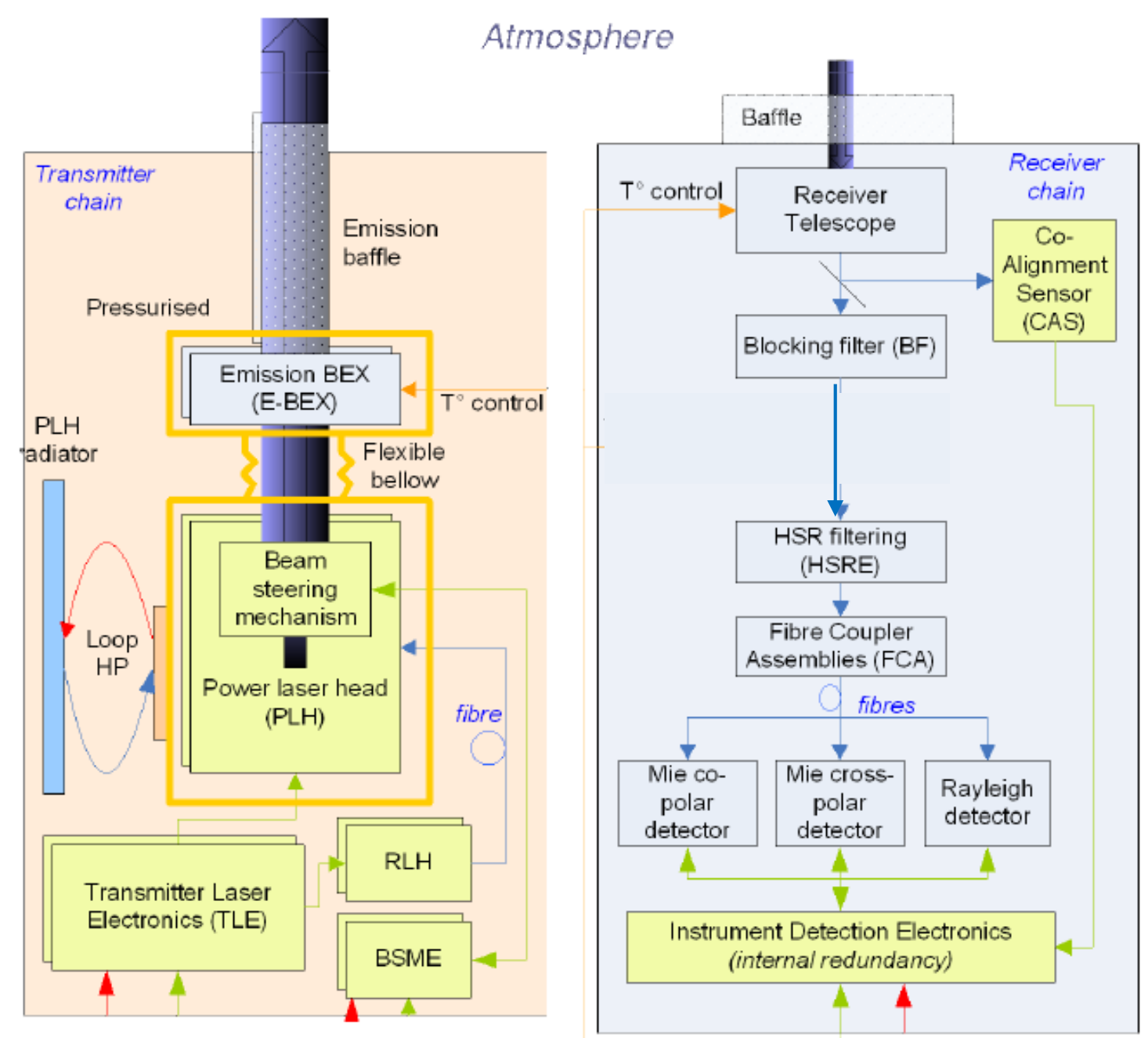

- $620 \mathrm{~mm}$ diameter telescope with coalignment sensor, spectral and spatial filtering before final High Spectral Resolution Etalon and polariser stage.

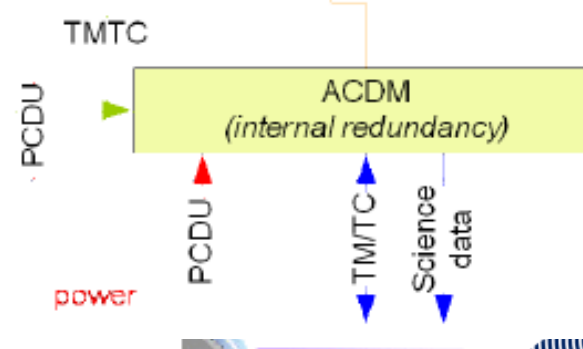




\section{ATLID instrument design}

- Bistatic architecture: separate transmitter and receiver, with active co-alignment loop

- Transmitter:

$$
\begin{array}{r}
\text { Telescope primary } \\
\text { mirror } \\
\text { M2 mirror Sun }
\end{array}
$$

- Pressurized power laser head 40mJ @51Hz, seeded by frequency adjustable reference laser and with beam steering mechanism

- Beam expander and external baffle to protect from contamination

- Fully redundant equipments.

\section{Emission baffles}

Emission beam expanders (EBEX)

Telescope support baseplate (TSB)

\section{- Receiver}

- $620 \mathrm{~mm}$ diameter telescope with coalignment sensor, spectral and spatial filtering before final High Spectral Resolution Etalon and polariser stage.

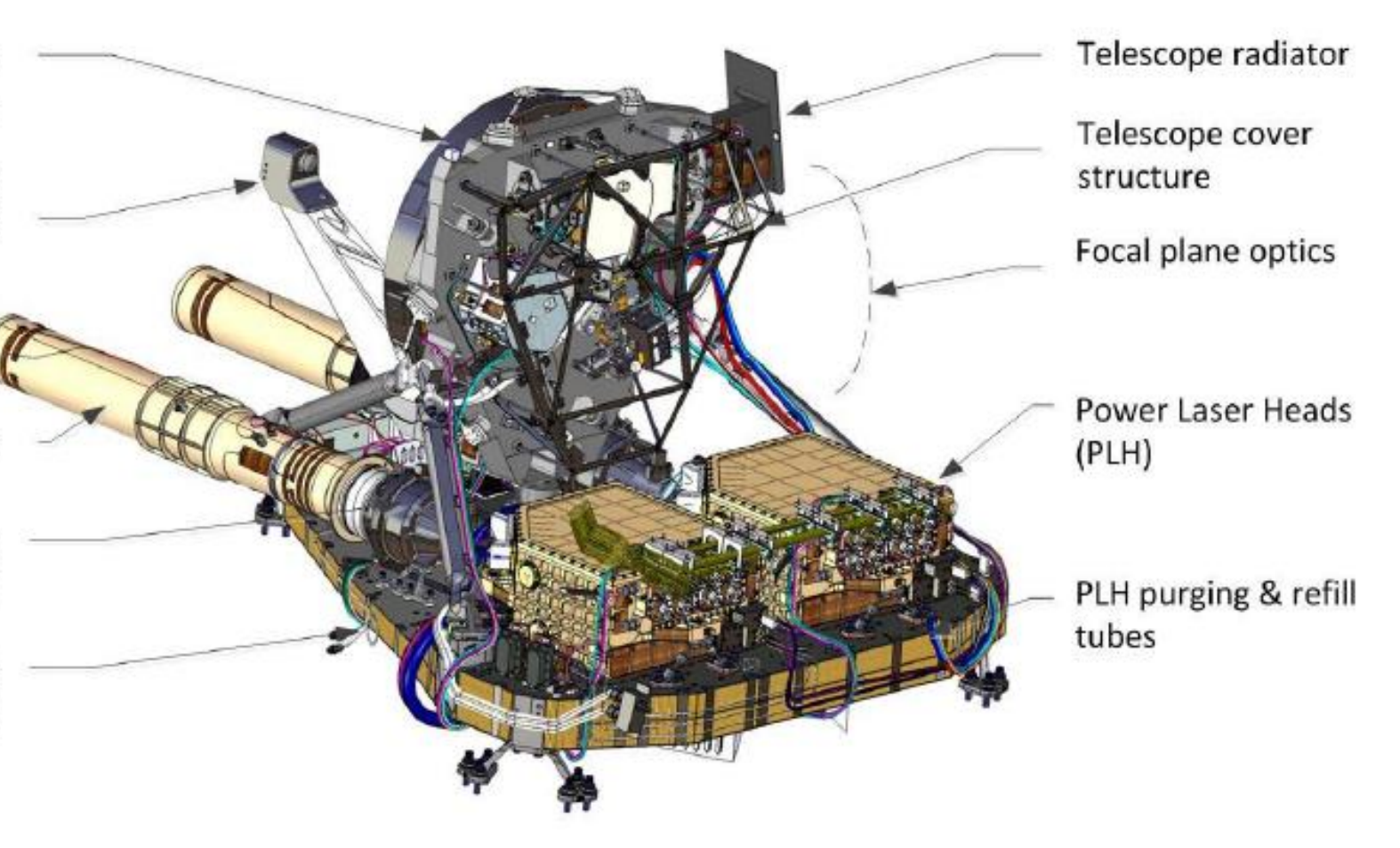

elescope radiator structure

Focal plane optics

Power Laser Heads (PLH)

LLH purging \& refill tubes 


\section{ATLID instrument development}

- ProtoFlight Model (PFM) development, is composed of:

- Electrical Flight Model (EFM)

- All flight electronics, detection and ATLID control data management (ACDM), integrated on housing structure assembly.

- Verification: functional, detection

- Optical Flight Model (OFM )

- All optical units from receiver and transmitter, stable structure assembly.

- Verification: optical performance mechanical stability
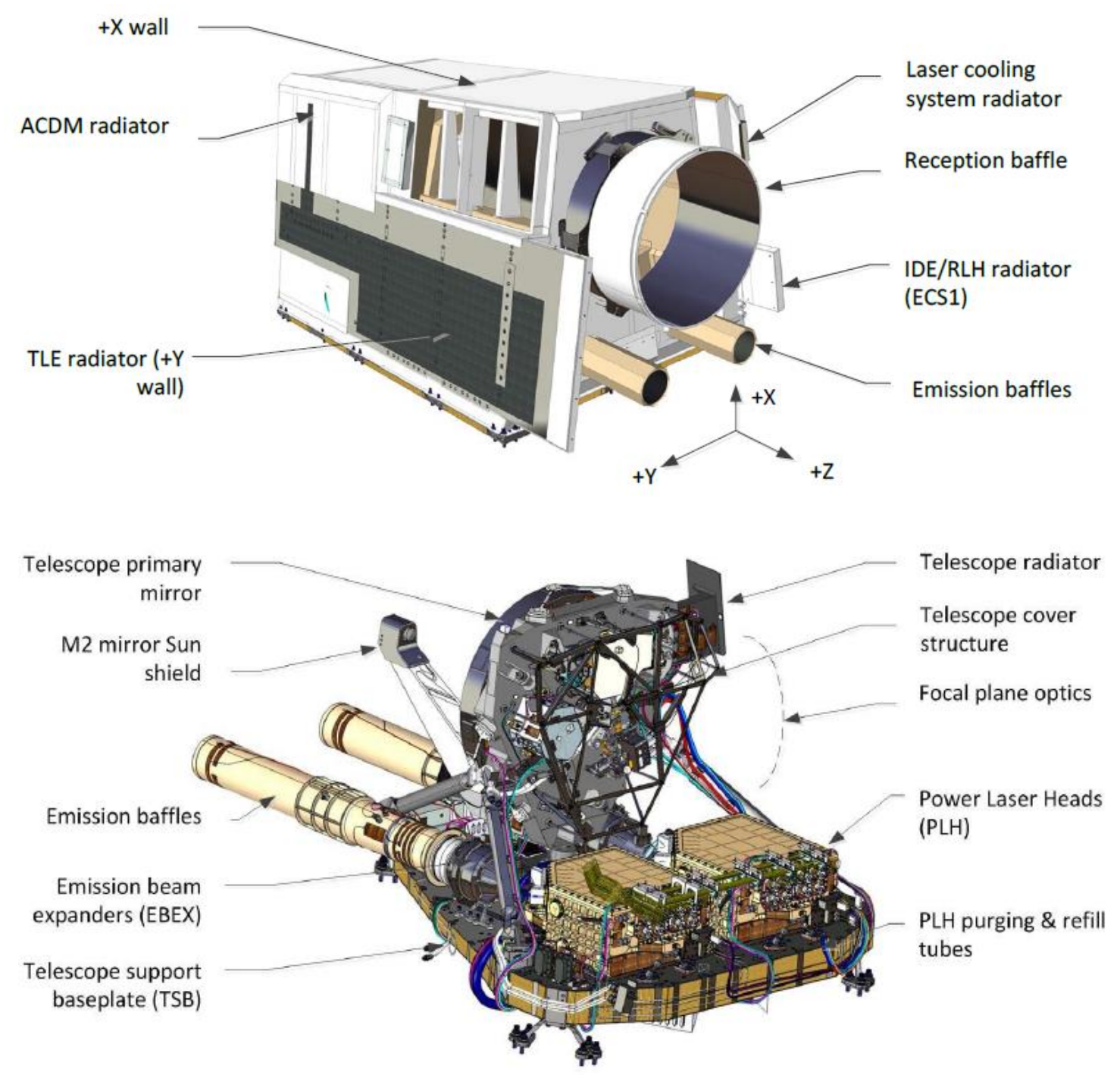

ATLID Esa AIRBus 


\section{ATLID instrument development}

- ProtoFlight Model (PFM) development, is composed of:

- Electrical Flight Model (EFM)

- All flight electronics, detection and ATLID control data management (ACDM), integrated on housing structure assembly.

- Verification: functional, detection

- Optical Flight Model (OFM )

- All optical units from receiver and transmitter, stable structure assembly.

- Verification: optical performance, mechanical stability

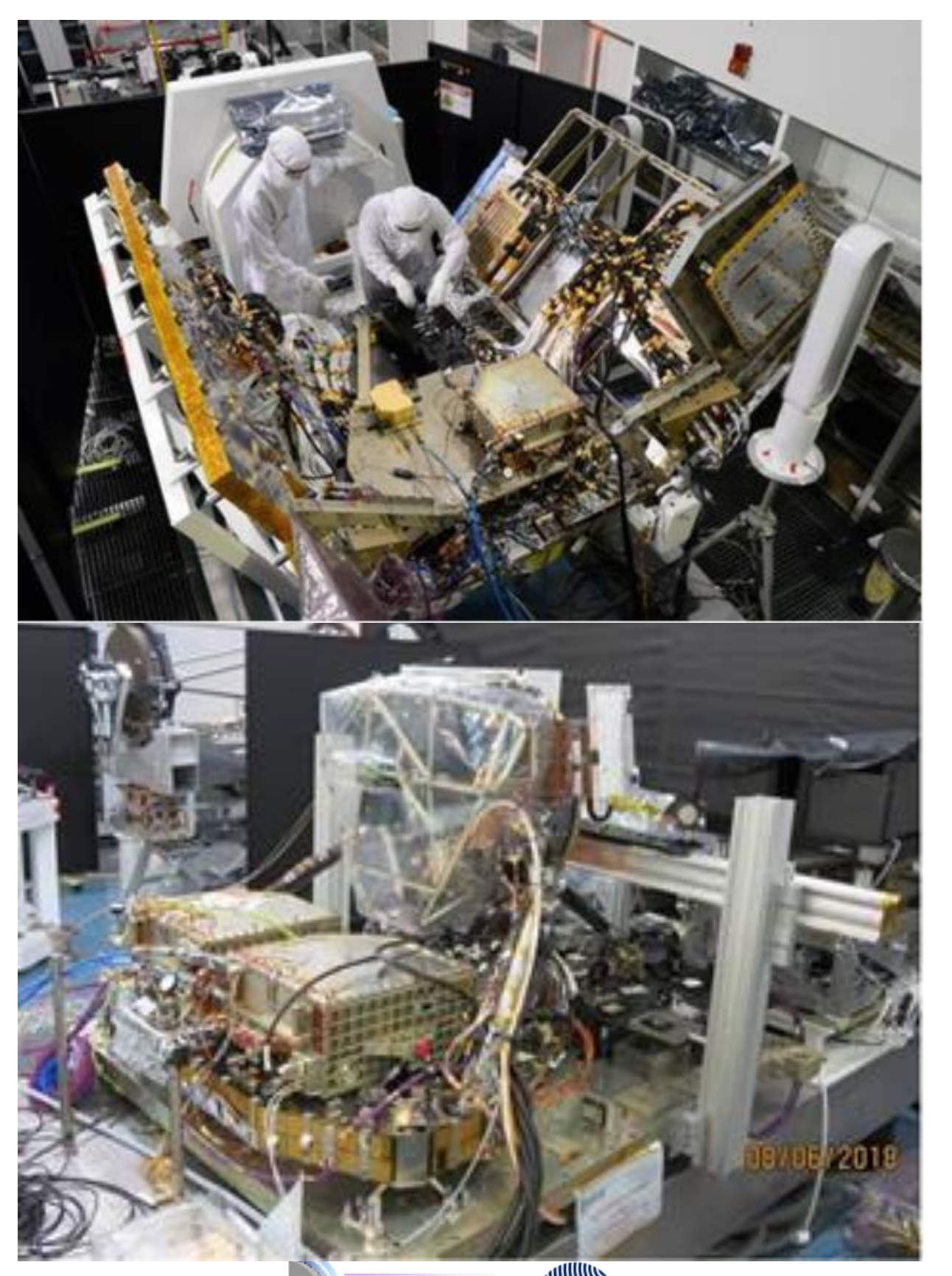


- ATLID and EarthCARE misson

- ATLID design and development

- ATLID flight model testing

- Mechanical test

- Radiometric test

- Detection test

- Functional test

- ATLID final integration steps

- ATLID environmental test campaign 


\section{ATLID OFM mech. testing}

- UNDER TEST: on OFM, all optical flight parts on receiver and of mechanical stable structure with structural model of transmitter parts.

- Verification of the Silicon Carbide structure of telescope and focal plane.

- Correlation with ATLID FEM model

- Validation of all maximum stress in particular in all bonded parts, like molecular adhesion of Fabry Perot Etalon.

- Validation of the transmitter to receiver stability within $100 \mu \mathrm{rad}$.

$\Rightarrow$ OFM mechanically validated
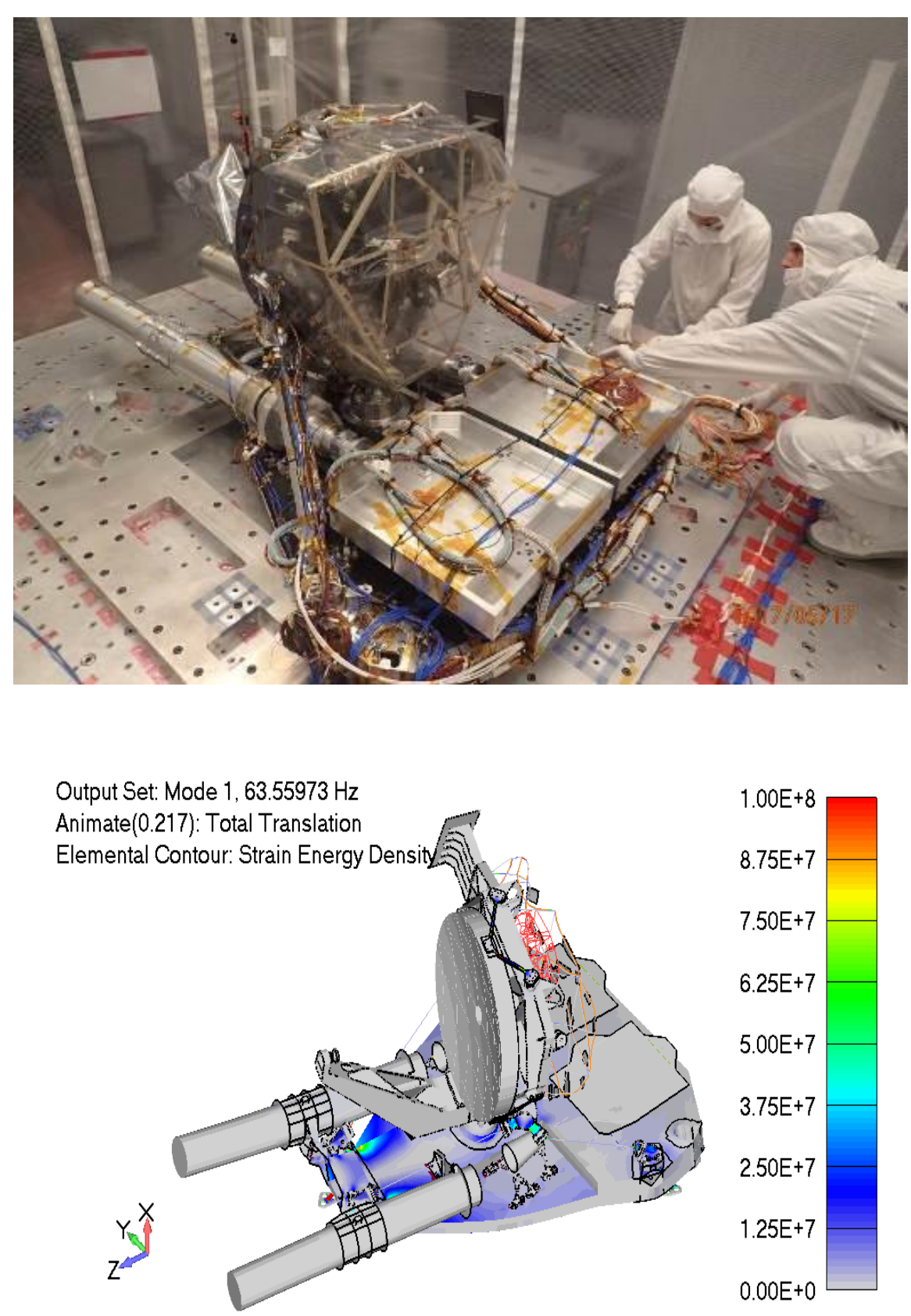


\section{ATLID radiometric performance}

- UNDER TEST: on OFM, all receiver optical parts functions:

- Spatial filtering with blocking filter limiting spatially the receiver field of view

- Spectral rejection of background

- High spectral Resolution Etalon Fabry Perot spectral profile

- 3 channels transmissions from telescope till fiber injection.

- Co alignment sensor (CAS)

$\Rightarrow$ OFM radiometric performance validated

\begin{tabular}{|c|c|}
\hline $\begin{array}{l}\text { OFM receiver } \\
\text { Characteristic }\end{array}$ & $\begin{array}{l}\text { Value measured on } \\
\text { ground }\end{array}$ \\
\hline RFOV diameter & 65 urad \\
\hline $\begin{array}{r}\text { Wide band transmission } \\
\text { outside interferometric } \\
\text { filter }\end{array}$ & $<0.01 \%$ \\
\hline $\begin{array}{r}\text { Mie-Copolar transmission } \\
\max \end{array}$ & $54 \%$ \\
\hline $\begin{array}{r}\text { Mie-Cross polar } \\
\text { transmission max }\end{array}$ & $60 \%$ \\
\hline $\begin{array}{r}\text { Rayleigh transmission } \\
\max \end{array}$ & $61 \%$ \\
\hline
\end{tabular}

Rayleieh Chennel RFov
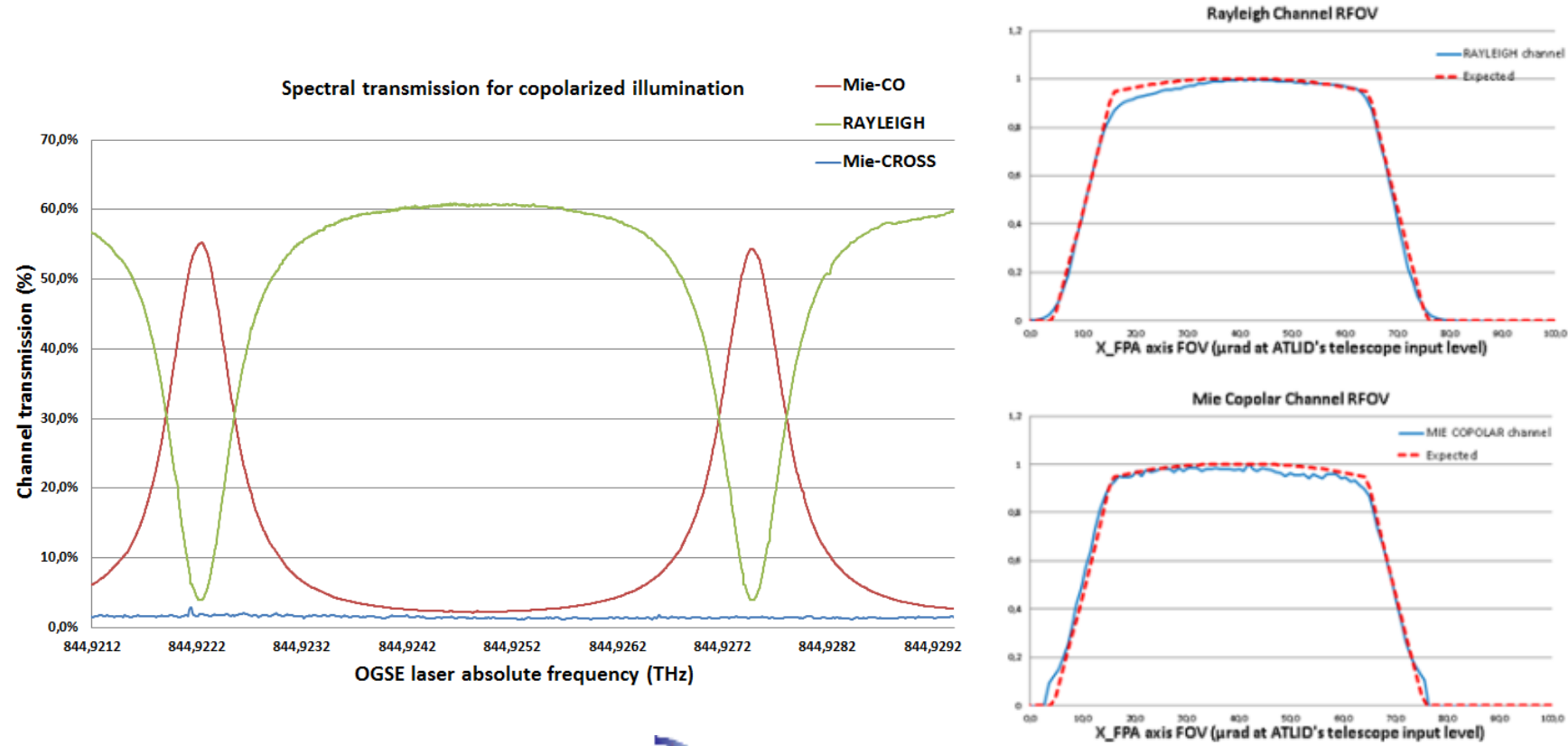

ATLID esa AIRBUS 


\section{ATLID detection performance}

- UNDER TEST: on EFM, all ATLID flight detection chain from fiber till detector and detection unit in representative flight conditions (TVAC):

- 3 Detector Fibre Assembly for the 3 channels

- Instrument Detection Electronics

- Use of UV modulated source de test detection performance in timing and in efficiency, and of EM model of ATLID Control and Data Management (ACDM) unit

\begin{tabular}{|r|l|}
\hline Characteristic & $\begin{array}{l}\text { ATLID EFM detection } \\
\text { measurement }\end{array}$ \\
\hline $\begin{array}{r}\text { Vertical crosstalk on } \\
\text { adjacent samples }\end{array}$ & $\begin{array}{l}4.5 \% \text { on } 500 \mathrm{~m}, 19 \% \text { on } \\
100 \mathrm{~m}\end{array}$ \\
\hline $\begin{array}{r}\text { Computed quantum } \\
\text { efficiency }\end{array}$ & $79 \% / 75 \% / 79 \%$ \\
MieCoPo/MieCross/Rayleigh & \\
\hline Linearity & $\begin{array}{l}<+/-1 \% \text { from } 10 \mathrm{e}-\text { to the } \\
\text { top } \\
\end{array}$ \\
$<+/-2 \%$ from $1 \mathrm{e}-$ to 10 e- \\
\hline $\begin{array}{r}\text { Dynamic margin on channels } \\
\text { wrt predicted worst signal }\end{array}$ & $18 \% / 5 \% / 12 \%$ \\
MieCoPo/MieCross/Rayleigh & \\
\hline Noise worst case & $2.2 \mathrm{e}-\mathrm{rms}$ \\
\hline
\end{tabular}

$\Rightarrow$ Detection performance validated 


\section{ATLID functional tests}

- UNDER TEST: on EFM, ATLID flight electronics controlled with ACDM flight unit:

- All modes operated with flight units with thousands of automated checks through 58 test procedures

- Switch on and transmitter parameter adjustment testing such as diodes currents and timings, harmonic generation crystals temperatures.

$\Rightarrow$ functional operation validated

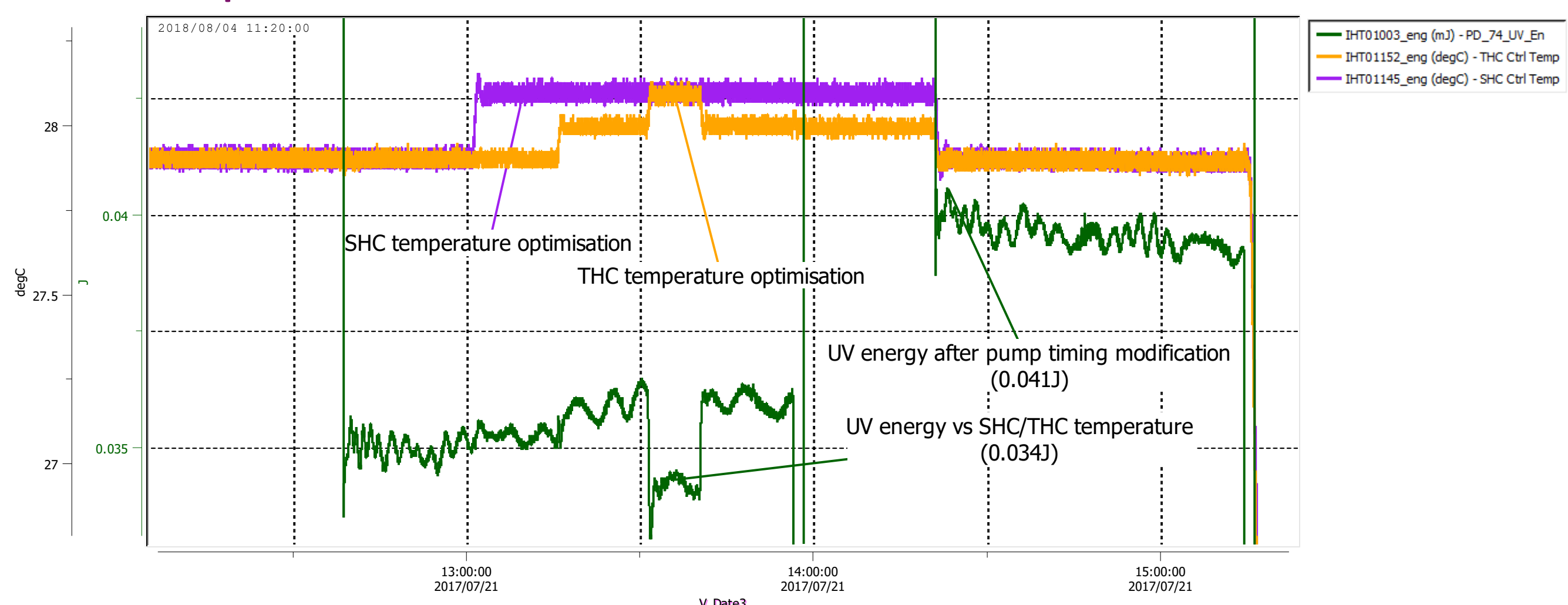


- ATLID and EarthCARE misson

- ATLID design and development

- ATLID flight model testing

- Mechanical test

- Radiometric test

- Detection test

- Functional test

- ATLID final integration steps

- ATLID environmental test campaign 


\section{ATLID last integration step}

- After validation of OFM and EFM, final integration steps is ongoing to integrate the laser cooling system (LCS), made of a network of 8 diphasic mini loop heat pipes.

- LCS is extracting the $150 \mathrm{~W}$ dissipation from the laser head toward +Y radiator with minimum mechanical load thanks to small size of loop heat pipe and their mechanical insulation of the radiator.

- It interfaces on OFM side with laser head, and on EFM side with Housing Structure assembly.
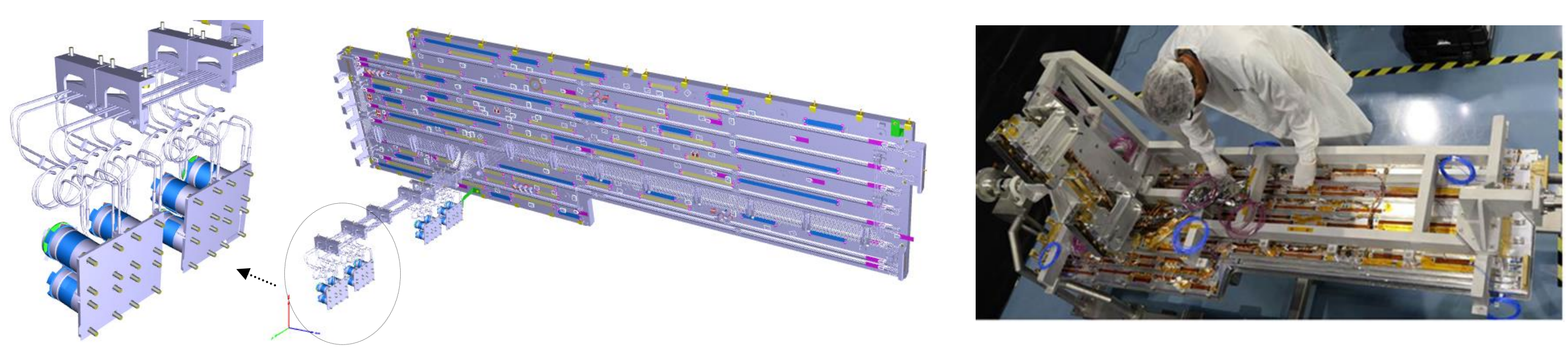


\section{ATLID last integration step}

- The LCS is integrated into the HSA that contains all EFM units

- The OFM is integrated into the HSA

- HSA is closed, EFM and OFM are definitevly coupled into ATLID PFM, ready for environment testing
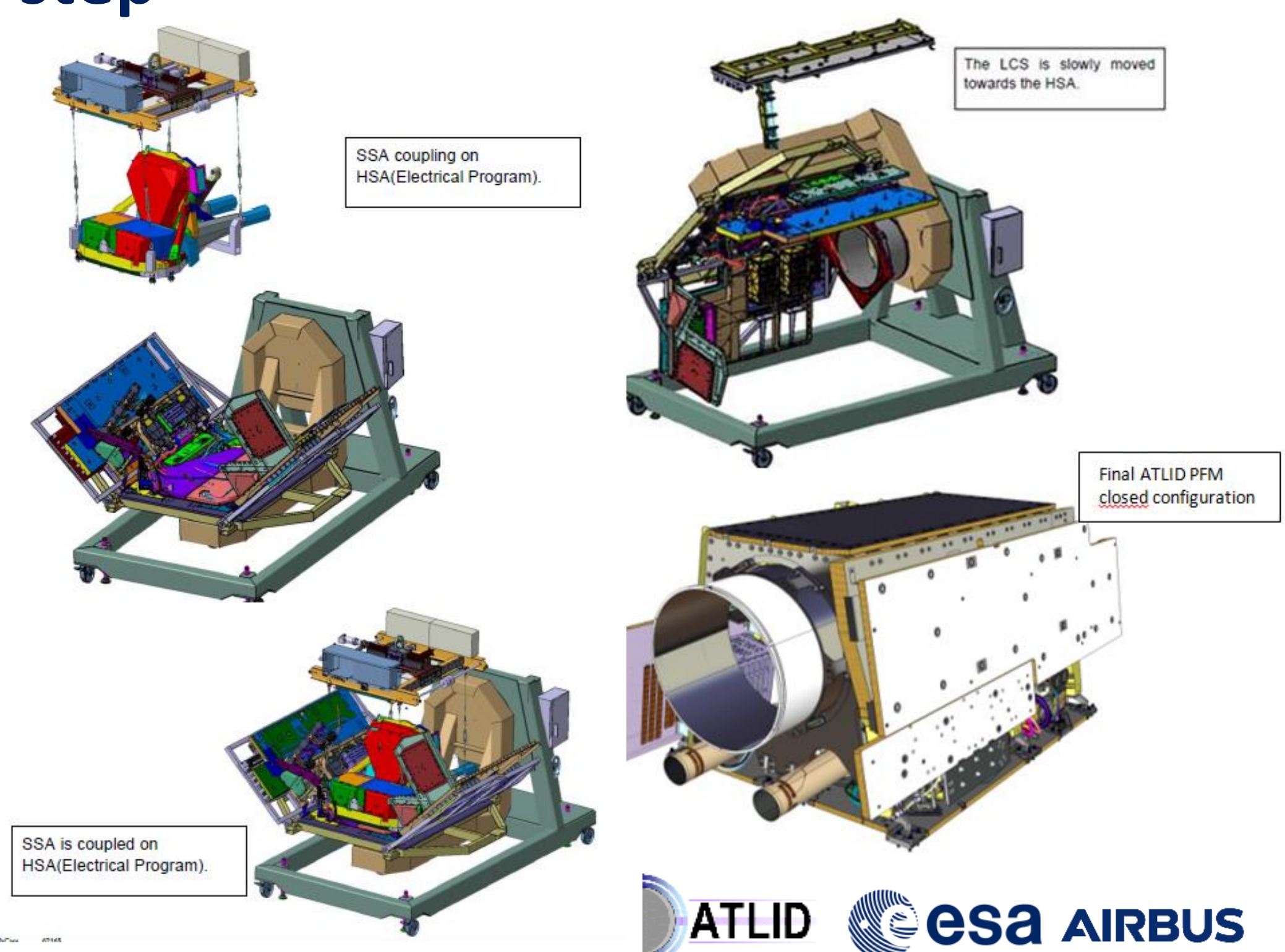

ATLID Eesa AIRBUS 


\section{ATLID last integration step}
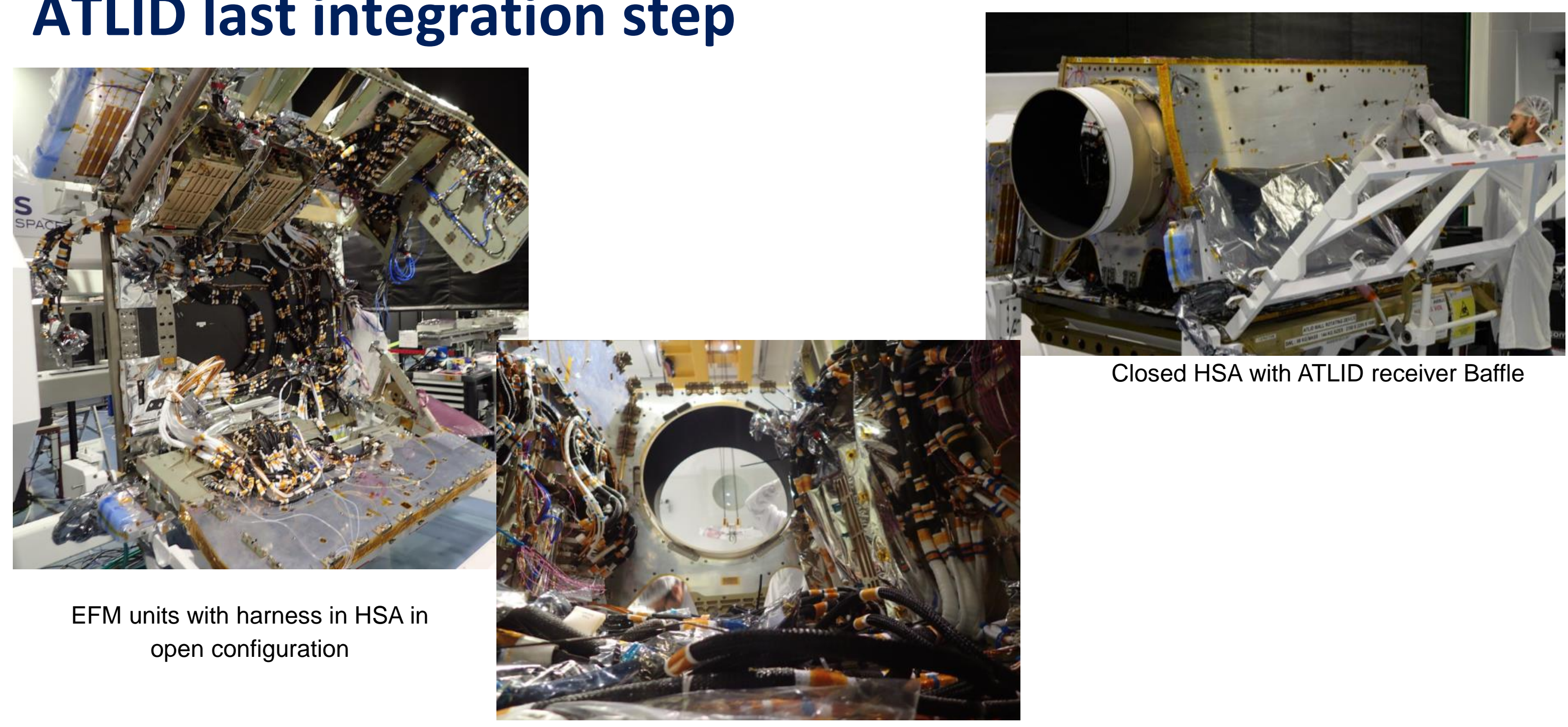

Closed HSA with ATLID receiver Baffle

View from inside closed HSA toward ATLID Baffle 


\section{ATLID last integration step}
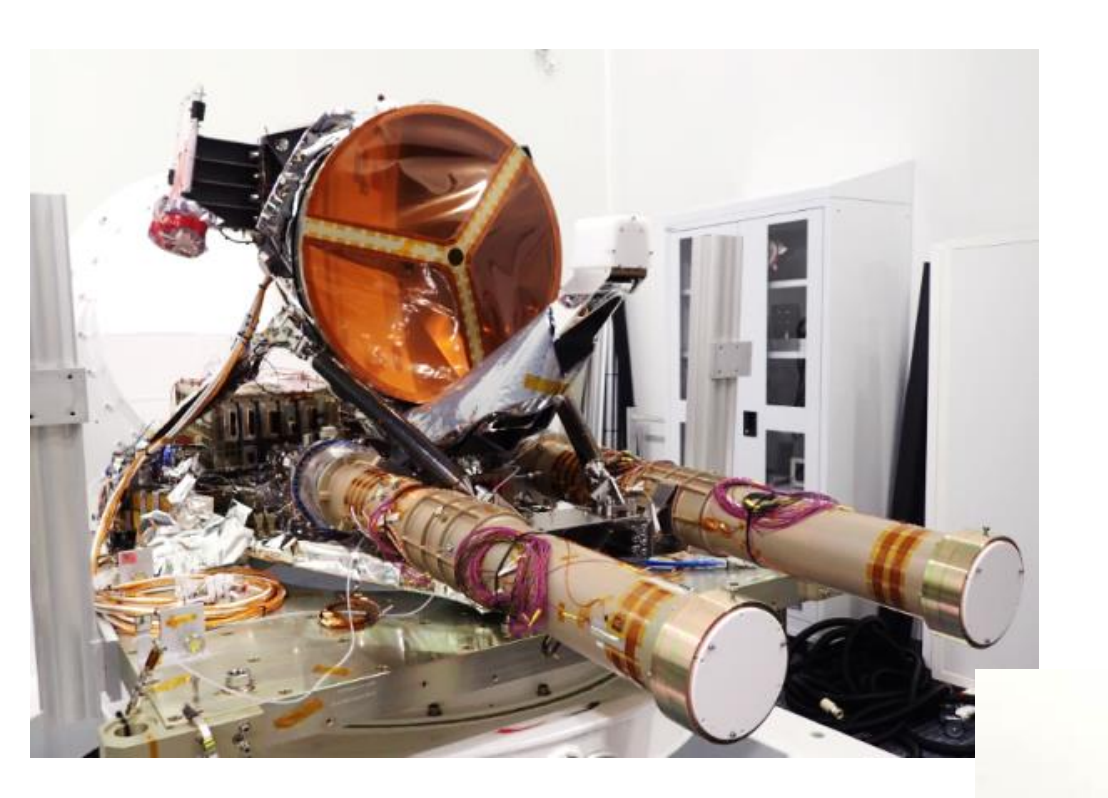

OFM before MLI integration

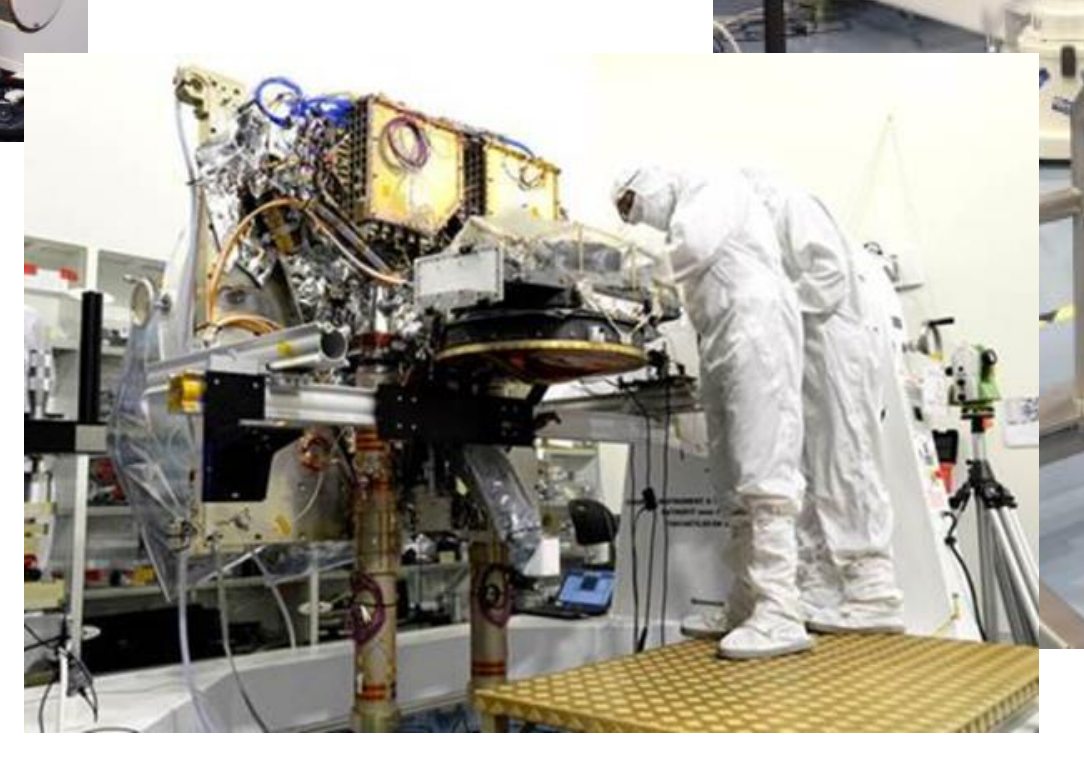


- ATLID and EarthCARE misson

- ATLID design and development

- ATLID flight model testing

- Mechanical test

- Radiometric test

- Detection test

- Functional test

- ATLID final integration steps

- ATLID environmental test campaign 


\section{ATLID ambient testing}

- Prior to environmental tests, ATLID complete instrument will be characterized at ambient with optical and performance characterisation, including also EMC testing

- Final verification can be closed when measurement at ambient is representative

- Ambient test is also mitigation step to validate OGSE setup, as rehearsal of final thermal vacuum test.
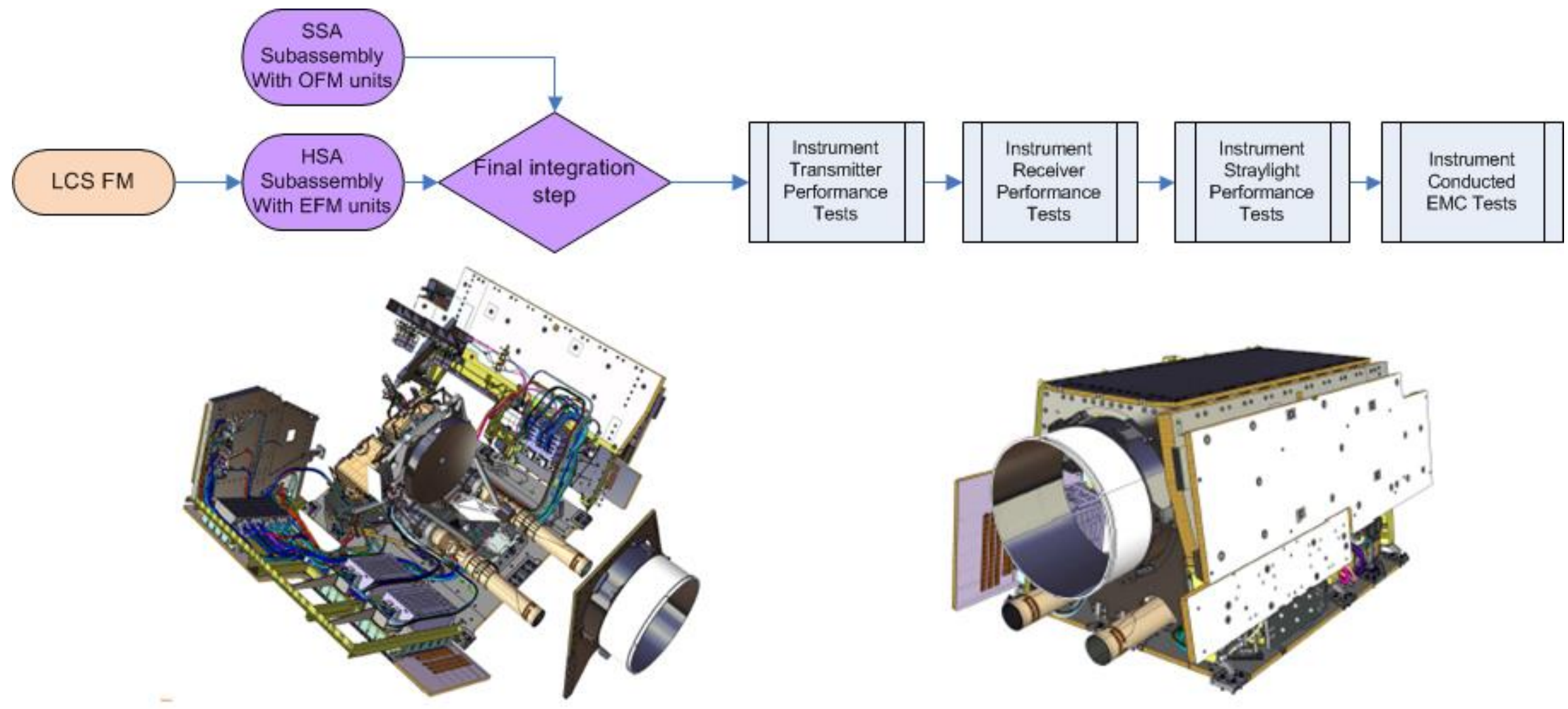


\section{ATLID vibration test}

- ATLID complete instrument will be vibrated in acoustic and sinus environment. It will close the mechanical verification of ATLID, in particular linked to the laser cooling system (LCS), last flight equipment that could not be mechanically tested in representative environment.

- The mechanical behaviour of LCS assembly including the 2 $\mathrm{mm}$ diameter pipe tubing under pressure is very dependent on its interface stiffness.

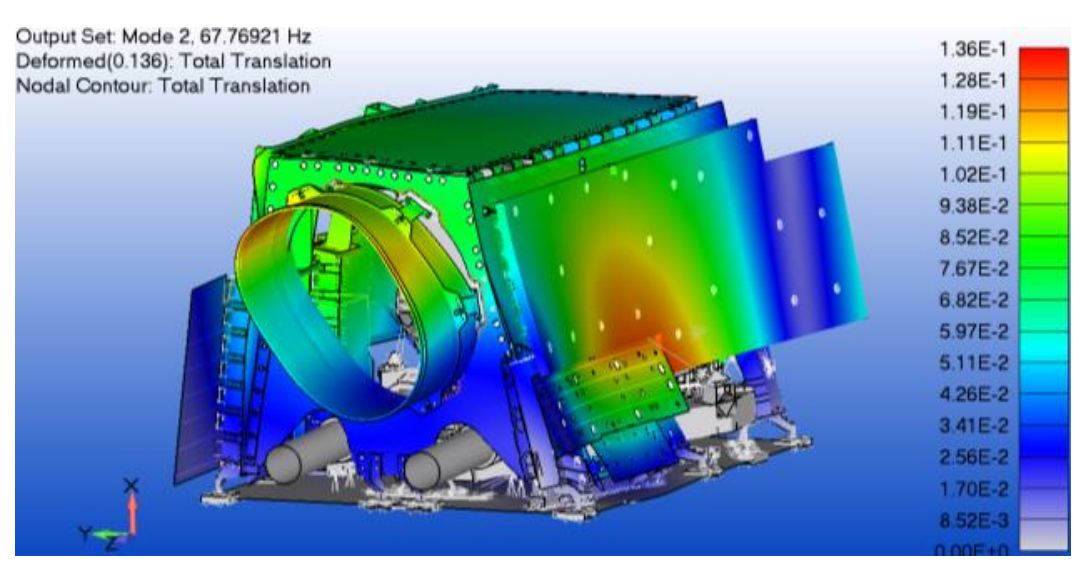

Main $\mathrm{HSA}(\mathrm{Y})$ mode@67.8 Hz

- Success Criteria will be based on instrument good health tests, with functional verification, stability measurement, and Laser Cooling System min loop heat pipe start up demonstration 


\section{ATLID thermal vacuum test}

Thermal shrouds around ATLID instrument
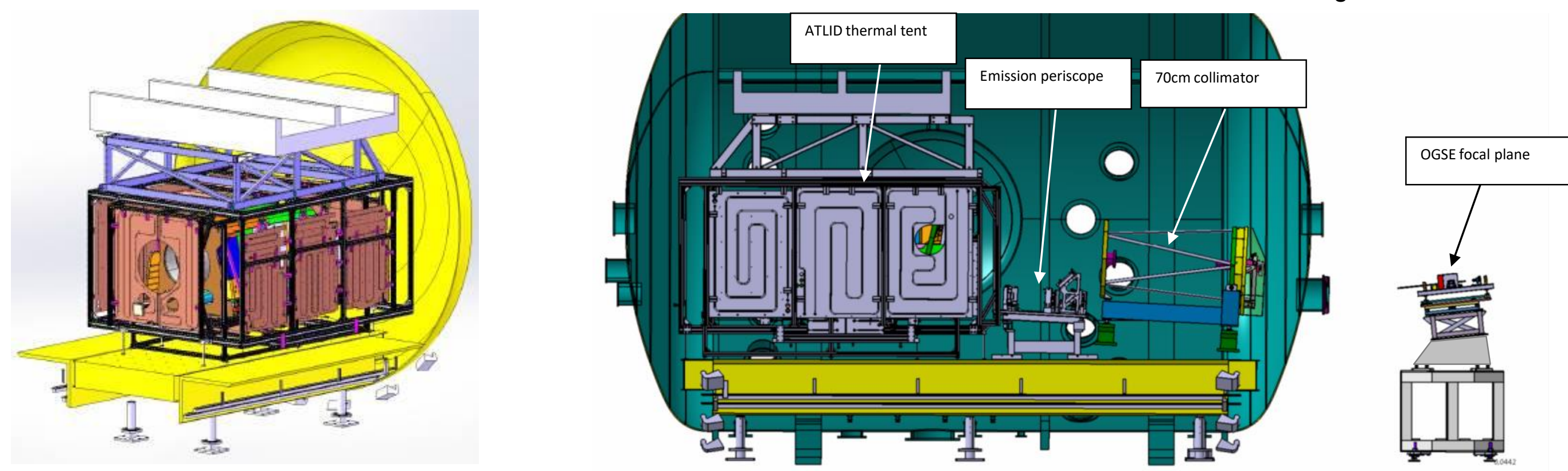

- Test is prepared at Centre Spatial de Liège as for ALADIN instrument.

- Thermal vacuum simulate all orbital life, including typical orbital variation (as example $100^{\circ} \mathrm{C}$ total range with $+Y$ sun flux variation) and demonstrate ATLID capability to maintain stable performances.

- Additional criticality to usual TVAC is Laser Induced Contamination (LIC) mitigation. The emission path flight optics at high fluence will be protected from contamination thanks to GSE UV window. A bake out will be performed after vacuum pumping. 


\section{CONCLUSION}

- All ATLID flight parts have been delivered and successfully qualified

- ATLID flight instrument has been successfully validated at OFM and EFM major development steps, with fünctional, performance, mechanical stability tests

- Today's ATLID activities focusses on

- Final integration step with OFM and EFM merge into the ATLID flight PFM

- Ambient testing, vibration and thermal vacuum test cámpaign

$\Rightarrow$ ATLID Dell very mid 2019

$\Rightarrow$ EC Launch

ATLID is one of the three spaceborne LIDAR developed by Airbus with ALADIN and MERLIN.

THANKS to all the ATLID team, to the industrial team, to our EarthCARE prime and our customer ESA !. 
Thank you for your attention! 